\title{
Improved Voltage Stability Boundary Monitoring by Accounting for Variations in Thevenin Voltage Magnitude.
}

\author{
Karatas, Bahtiyar Can; Jóhannsson, Hjörtur; Nielsen, Arne Hejde
}

Published in:

Proceedings of 8th IEEE PES Innovative Smart Grid Technologies Conference

Link to article, DOI:

10.1109/ISGTEurope.2018.8571648

Publication date:

2018

Document Version

Peer reviewed version

Link back to DTU Orbit

Citation (APA):

Karatas, B. C., Jóhannsson, H., \& Nielsen, A. H. (2018). Improved Voltage Stability Boundary Monitoring by Accounting for Variations in Thevenin Voltage Magnitude. In Proceedings of 8th IEEE PES Innovative Smart Grid Technologies Conference IEEE. https://doi.org/10.1109/ISGTEurope.2018.8571648

\section{General rights}

Copyright and moral rights for the publications made accessible in the public portal are retained by the authors and/or other copyright owners and it is a condition of accessing publications that users recognise and abide by the legal requirements associated with these rights.

- Users may download and print one copy of any publication from the public portal for the purpose of private study or research.

- You may not further distribute the material or use it for any profit-making activity or commercial gain

- You may freely distribute the URL identifying the publication in the public portal 


\title{
Improved Voltage Stability Boundary Monitoring by Accounting for Variations in Thevenin Voltage Magnitude
}

\author{
Bahtiyar Can Karatas, Hjörtur Jóhannsson and Arne Hejde Nielsen \\ Department of Electrical Engineering \\ Technical University of Denmark \\ Kgs. Lyngby, Denmark
}

\begin{abstract}
This paper identifies weakness of existing method for voltage stability assessment and proposes new approach for determining point of maximum deliverable power to a given load that accounts for the variations in the Thevenin voltage magnitude. The approach uses Thevenin equivalents seen from nodes of constant voltage magnitude and load nodes in order to determine a distance to instability. A simple five-bus system together with IEEE 14 bus system were used in order to perform dynamic simulation in PSS/E. The simulation data were used to create synthetic Phasor Measurement Unit (PMU) snapshots, which served as input to the proposed approach. The new approach is demonstrated on the two test systems, where improved accuracy in determining the point of maximum deliverable power is demonstrated. The results show that the point of maximum deliverable power to the load occurs well before the Thevenin impedance matching criteria.
\end{abstract}

\section{INTRODUCTION}

Modern power systems rely on stable and secure supply of power and are steadily including more renewable energy sources (RES) with the purpose of reducing $\mathrm{CO} 2$ emissions [1]. Many countries have set ambitious targets for integration of RES where eg. in Denmark the future goal by 2050 is to be independent of fossil fuels [2]. Considering the fluctuating nature of RES, it is foreseen to cause that existing time consuming offline approaches become insufficient in ensuring stable and secure system operation. These obstacles introduce the need for methods capable of ensuring system stability in real-time.

Recent research has focused on how stability and system security may be assessed in real-time. Examples of assessments based on algebraically derived boundaries enabled assessment in the millisecond range [3]-[5]. The fast computation of Thevenin equivalents [5] creates opportunity for fast assessment of voltage stability. Other recent research conducted [6] focused on methods usable for assessing voltage stability [7], [8]. The focus was on long-term voltage stability and several methods were investigated [9], [10]. One approach found fitting for real-time assessment of voltage stability for longterm cases was based on the Thevenin Equivalent Method

This work is part of the Danish research project Security Assessment of Renewable Power Systems (SARP), which was received funding from the Danish TSO Energinet.dk as part of their ForskEL-programme

978-1-5386-4505-5/18/\$31.00 C)2018 IEEE
(TEM) [11]-[13]. Several improvements to the TEM approach were investigated, which considered synchronous generator limits, wind-farm limits and the impact an HVDC interconnection has on voltage stability [14]-[16].

This paper identifies weaknesses in existing Thevenin based methods and proposes an improved approach that overcomes this weakness. The improved approach determines the maximum deliverable power to a load, which includes the changes in the Thevenin voltage seen from a load. The approach is compared to an existing method, which is based on the Thevenin impedance matching criteria [12].

The structure of the paper is as follows. Section II describes Thevenin based assessment methods and its limitations and the improved approach. Section III shows the simulation results on the two test systems and finally in Section IV the conclusion is summarized.

\section{THEVENIN EQUIVALENT METHOD}

\section{A. Traditional method}

The Thevenin equivalent method is based on the two-bus equivalent [12] seen from the non-controlled (nc) voltage bus as represented in Fig. 1 where the load impedance is written as $\bar{Z}_{L D}=\left|Z_{L D}\right| \angle \gamma_{L D}=R_{L D}+j X_{L D}$.

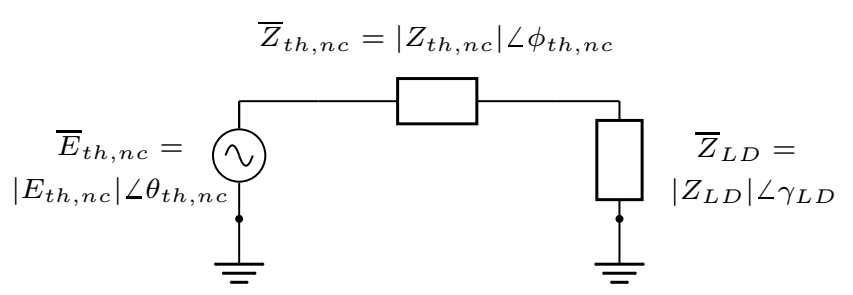

Fig. 1. Thevenin equivalent seen from load, which is used for estimating how $\left|E_{t h, n c}\right|$ behaves with respect to the load impedance $\left|Z_{L D}\right|$

The two-bus equivalent can be determined by using measurement data provided by synthetic PMU snapshots. The active load power can be determined based on the Thevenin equivalent as: 


$$
P_{L D}=\left|\frac{\bar{E}_{t h, n c}}{\bar{Z}_{t h, n c}+\bar{Z}_{L D}}\right|^{2} R_{L D}
$$

In [17], a voltage stability index (VSI) is used, which is defined as:

$$
V S I=1-\frac{\left|Z_{t h, n c}\right|}{\left|Z_{L D}\right|}
$$

where the condition $\left|Z_{t h, n c}\right|=\left|Z_{L D}\right|$ represents the Thevenin matching criteria, under the assumption that the Thevenin voltage $E_{t h, n c}$ seen from the load remains constant. The VSI provides a distance to instability and as it reaches zero, the maximum power transfer to the load is reached.

\section{B. Approach considering changes in the Thevenin voltage seen from the load}

To determine the maximum power transfer to a load with changes in the Thevenin voltage seen from the load, two assumptions are necessary:

- Power is injected into nodes of constant voltage magnitude. The synchronous generators are represented as a voltage source $V \angle \delta$ and depending on the excitation system, the voltage source is directly connected to the generator terminals if an automatic voltage regulator (AVR) is present, or the voltage source is connected behind the synchronous reactance $X_{d}$. In the latter case, the generator is manually excited or the over-excitation limiter (OXL) has been activated.

- The second assumption is that loads are represented by their impedance values. The approach needs the instantaneous representation of the system condition in order to correctly determine the change in Thevenin voltage seen from the load.

These assumption are valid by receiving synthetic PMU snapshots at a high rate. Based on the assumptions, the Thevenin equivalent seen from a voltage-controlled (vc) node can be represented as seen in Fig. 2.

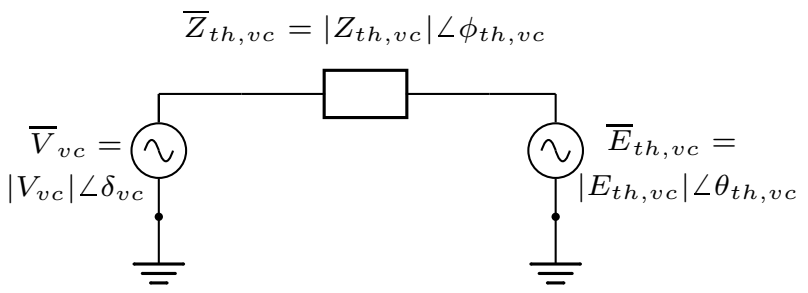

Fig. 2. Thevenin equivalent seen from a generator, which is used to estimate how the generator angle $\delta_{v c}$ behaves with respect to load impedance change $\left|Z_{L D}\right|$

By assuming that the voltage at both ends in the equivalent system are constant and the impedance $Z_{t h, v c}$ is fixed, the active power injection is given as:

$P_{i n j}=\frac{V_{v c}^{2}}{Z_{t h, v c}} \cos \left(\phi_{t h, v c}\right)-\frac{E_{t h, v c} V_{v c}}{Z_{t h, v c}} \cos \left(\delta_{v c}+\phi_{t h, v c}-\theta_{t h, v c}\right)$
Rewriting (3) an expression for the generator angle $\delta_{v c}$ can be obtained:

$\delta_{v c}=\arccos \left(\frac{V_{v c}^{2} \cos \phi_{t h, v c}-P_{i n j} Z_{t h, v c}}{E_{t h, v c} V_{v c}}\right)+\theta_{t h, v c}-\phi_{t h, v c}$

By representing loads by their impedance values, the Thevenin equivalent obtained from a vc node will include the load impedances. Also by knowing that power is injected into nodes of constant voltage magnitude, for each change in load impedance, the Thevenin equivalent seen from the $\mathrm{vc}$ node will change and the corresponding generator angle $\delta_{v c}$ can be estimated by using (4). For each change in load impedance, it is analyzed whether the estimated $\delta_{v c}$ represents stable conditions. The $P-\delta$ curves seen in Fig. 3 are useful for illustrating the estimated $\delta_{v c}$ angle. Initially the system conditions are stable, which is represented by the solid curve in Fig. 3 that intersects twice with the line of constant mechanical input power, where the operating points $O P_{1}$ and $O P_{2}$ correspond to a stable and unstable equilibrium respectively. By increasing the load power, the rotor angle will eventually reach the critical operating point $O P_{3}$, which is represented by the dashed curve. A further increase in load power beyond the critical operating point $O P_{3}$ represents unstable conditions with no equilibrium, which is represented by the dotted curve. All the load impedance values and their corresponding $P-\delta$ curves that intersect with the line of constant mechanical input power are used to estimate the Thevenin voltage $E_{t h, n c}$ seen from the load, which consists of contributions of each generator in the power system. The estimated Thevenin voltage is used in (1) to determine the maximum deliverable power to the load.

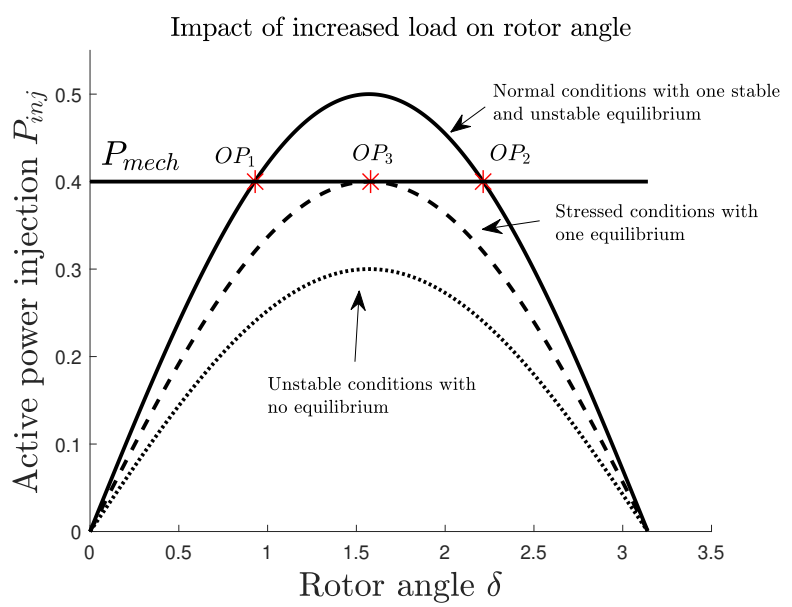

Fig. 3. $P-\delta$ curves for three scenarios: For the solid characteristic, the line of constant $P_{\text {mech }}$ intersects twice, where the left hand side represents stable operation. For the dashed characteristic, $P_{\text {mech }}$ intersects exactly once and for the dotted characteristic it never intersects.

Fig. 4 provides an overview of the proposed approach in determining the maximum deliverable power to the load by including the changes in Thevenin voltage $E_{t h, n c}$. 


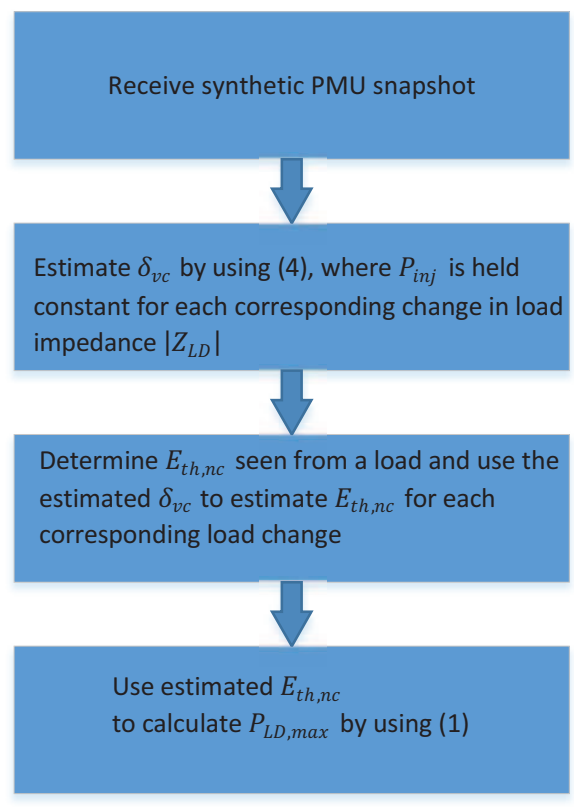

Fig. 4. Proposed approach to determine maximum power transfer to load. Initially the Thevenin equivalents seen vc and nc nodes are determined and afterwards the rotor angle $\delta_{v c}$ is estimated with respect to load impedance change $\left|Z_{L D}\right|$. The estimated $\delta_{v c}$ is used to estimate $\left|E_{t h, n c}\right|$ seen from a load to calculate $P_{L D, \max }$.

To illustrate the proposed approach and compare it with the Thevenin matching criteria, the simple five-bus system shown in Fig. 5 is analyzed.

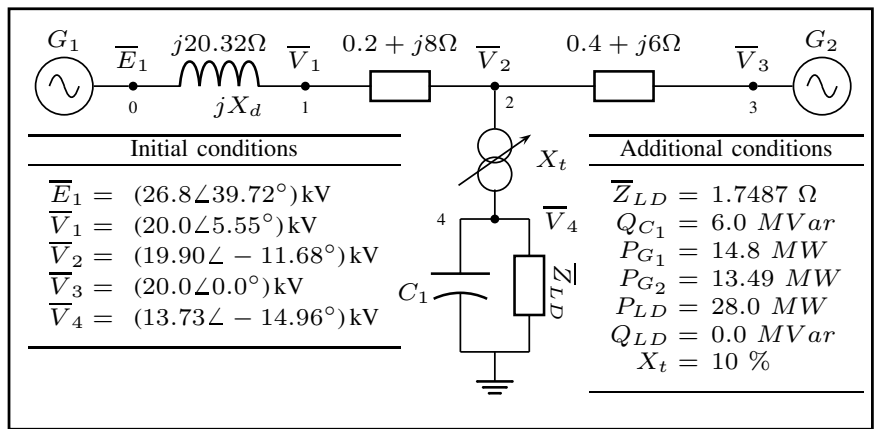

Fig. 5. Simple five-bus system to test the proposed approach. Generator $G_{1}$ is manually excited and operated with constant mechanical input power and generator $G_{2}$ represents an infinite bus $(H \rightarrow \infty)$.

TABLE I

PARAMETERS FOR OLTC TRANSFORMER

$\begin{array}{cccc}\text { Transformer } & \text { First tap delay }[\mathrm{s}] & \text { Tap time }[\mathrm{s}] & \text { Subsequent tap delay }[\mathrm{s}] \\ 301-101 & 30 & 1 & 9\end{array}$

Generator $G_{2}$ at bus 3 is modelled as an infinite bus where the voltage remains constant during the analysis. Generator $G_{1}$ at bus 0 represents a manually excited machine that operates with constant mechanical input power, which is represented as a constant voltage source seen behind the synchronous reactance $X_{d}$. The model parameters for $G_{1}$ can be found in [18]. The transformer between bus 2 and 4 is equipped with an On Load Tap Changer (OLTC). The OLTC keeps the low voltage side in the deadband $\left[\begin{array}{ll}0.97 & 1.00\end{array}\right]$ pu. Additaionally, the OLTC adjusts the transformer ratios in the range [ 0.88 1.12] over 24 positions. The load connected to bus 4 is resistive with a value of $28 \mathrm{MW}$ and the two generators share the production. Additionally, a shunt capacitor is also connected to bus 4 . The parameters used for the OLTC transformer can be seen in Table I. To analyze the initial conditions, the load is represented by its impedance value $\bar{Z}_{L D}$. In the five-bus test system, power is injected at nodes of constant steady state voltage magnitudes, which means the possible operating points of the system can be determined by obtaining information of the phase angle difference $(\Delta \delta)$ between the two nodes of constant voltage magnitude and the value of the load impedance $\bar{Z}_{L D}$. By fixing the load angle, the system operating points can be described by $(\Delta \delta)$ and the magnitude of the load impedance $Z_{L D}$ [18]. To analyze the initial operating conditions, the load angle has a constant value of $\phi=0^{\circ}$. Now the active power injection of $G_{1}$ into the node of constant voltage magnitude and the power delivered to the load $P_{L D}$ with respect to change in the two variables $(\Delta \delta)$ and $Z_{L D}$ can be visualized. Fig. 6 shows the combined contours of constant injected power $P_{G 1}$ (red contours) and constant power delivered to the load $P_{L D}$ (blue contours) and they are expressed in $M W$. Each of the contours describe the possible trajectory of the operating points.

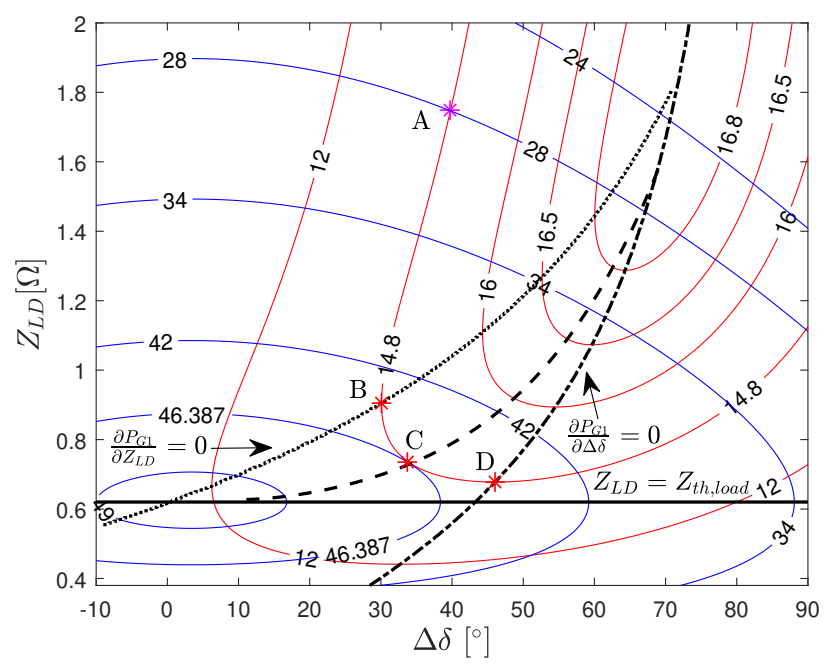

Fig. 6. Contours of constant injected power $P_{G 1}$ and constant power delivered to the load $P_{L D}$ in the $\Delta \delta-Z_{L D}$ plane. Point A represents the initial operating point. Point $\mathrm{C}$ represents the point of maximum deliverable power to the load and point D represents the rotor angle stability boundary for $G_{1}$.

Based on the initial conditions given in Fig. 5, the initial operating point is represented by point $\mathrm{A}$, which is also where the contour of $P_{G 1}\left(\Delta \delta, Z_{L D}\right)=14.8 \mathrm{MW}$ and $P_{L D}\left(\Delta \delta, Z_{L D}\right)=$ $28 M W$ intersect. Four characteristic lines are present in Fig. 6. The first black line $\frac{\partial P_{G 1}}{\partial Z_{L D}}=0$ describes the maximum injectable power when $\Delta \delta$ is fixed, which intersects with the contour of $P_{G 1}\left(\Delta \delta, Z_{L D}\right)=14.8 \mathrm{MW}$ at point $\mathrm{B}$. The 
second black line $\frac{\partial P_{G 1}}{\partial \Delta \delta}=0$ describes the maximum injectable power when $Z_{L D}$ is fixed, which intersects with the contour of $P_{G 1}\left(\Delta \delta, Z_{L D}\right)=14.8 \mathrm{MW}$ at point $\mathrm{D}$. The black horizontal line represents when the load impedance magnitude $Z_{L D}$ is equal to the thevenin impedance magnitude $Z_{t h \text {,load }}$ seen from the load. The black dashed line represents the maximum deliverable power to the load and it is characterized as the single intersection between two contours, when $G_{1}$ operates with constant mechanical input power. The point of maximum deliverable power to the load for the given initial conditions is highlighted as point $\mathrm{C}$. The two characteristic lines of interest are the horizontal line and the black dashed line that represents the voltage stability boundary of the load. The Thevenin matching criteria method is valid when the Thevenin voltage magnitude seen from the load remains constant with respect to changes in load impedance $Z_{L D}$. By considering Fig. 6 and for a fixed angle $\Delta \delta$ with respect to changes in $Z_{L D}$ results in the Thevenin voltage seen from the load to be constant. Therefore the point of maximum deliverable power to the load would occur when the load impedance magnitude $Z_{L D}$ equals the Thevenin impedance magnitude $Z_{t h, l o a d}$ seen from the load as represented by the horizontal line. In the fivebus test system $G_{1}$ operates with constant mechanical input power and based on the initial conditions, the contour of $P_{G 1}\left(\Delta \delta, Z_{L D}\right)=14.8 \mathrm{MW}$ represents the trajectory of the system operating conditions. Here it can be seen that changes in the load impedance magnitude $Z_{L D}$ results in changes in $\Delta \delta$. These changes in $\Delta \delta$ means that the Thevenin voltage magnitude seen from the load will not be constant and the maximum deliverable power to the load cannot be described by the horizontal line. The actual maximum deliverable power to the load is represented by the black dashed line and for the given initial conditions, point $\mathrm{C}$ is reached for a $Z_{L D}$ value higher than the Thevenin impedance magnitude $Z_{t h, l o a d}$. Therefore the Thevenin matching based method would not be able to detect voltage instability in this case, because the horizontal line does not intersect with the trajectory of operating points corresponding to $P_{G 1}\left(\Delta \delta, Z_{L D}\right)=14.8 \mathrm{MW}$. If $G_{1}$ was operating with constant mechanical input power corresponding to $12 M W$, the contour would intersect the horizontal line and the VSI method from (2) would detect voltage instability.

\section{Simulation RESUlTS}

\section{A. Simple 5 bus test system}

A time domain simulation was performed in PSS/E of the five-bus system given in Fig. 5. To provoke instability, the shunt capacitor located at bus 4 was disconnected at $t=5 \mathrm{~s}$ into the simulation. Fig. 7 show plots of bus voltage magnitudes of the high and low voltage side of the transformer and the internal rotor angle $\delta_{1}$ of $G_{1}$.
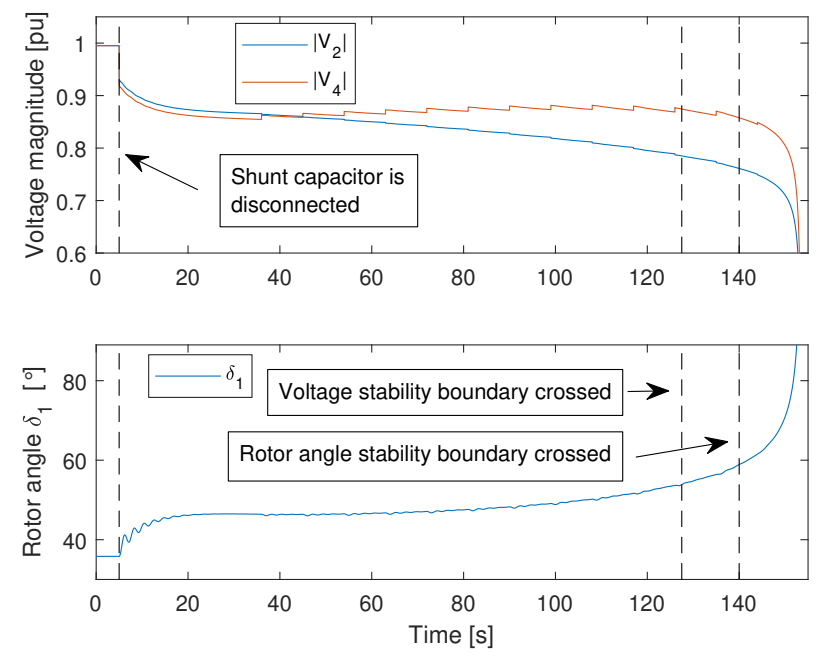

Fig. 7. Bus voltage magnitudes at selected buses and the internal rotor angle $\delta_{1}$.

The disconnection of the shunt capacitor causes the voltage to drop below $0.9 \mathrm{pu}$ and at $t=38 \mathrm{~s}$ the OLTC transformer initiates the first tap change to start recovering the voltage $\left|V_{4}\right|$. With each tap change, $\left|V_{4}\right|$ slowly recovers but the high voltage side of the transformer $\left|V_{2}\right|$ slowly declines. At $t=127.2 \mathrm{~s}$, the point of maximum deliverable power to the load is reached due to the tap changes. The contours of $P_{G 1}$ and $P_{L D}$ can be seen in Fig. 8.

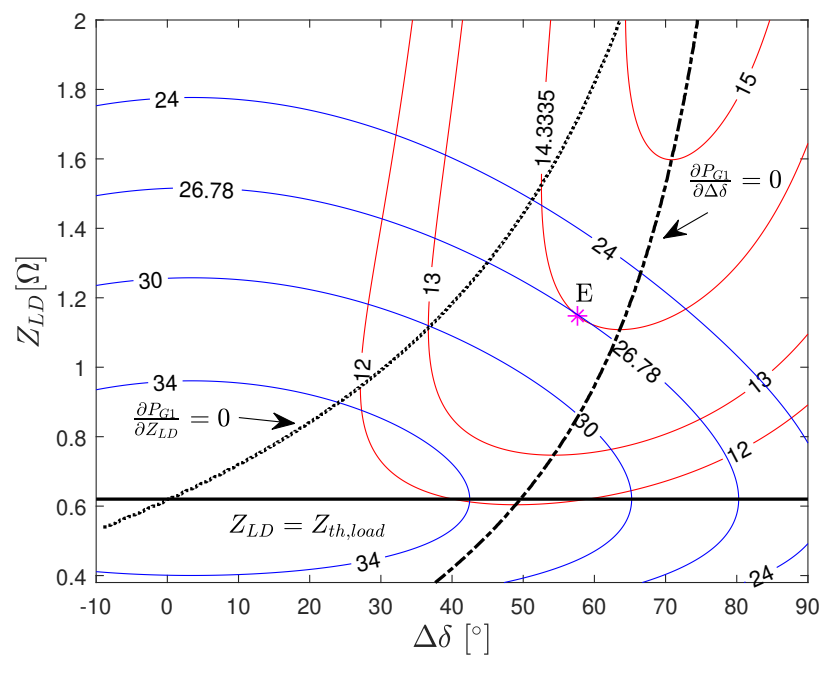

Fig. 8. Contours of constant injected power $P_{G 1}$ and constant power delivered to the load $P_{L D}$ in the $\Delta \delta-Z_{L D}$ plane at $t=127.2 s$.

Each consecutive tap change caused the load impedance magnitude $Z_{L D}$ to decrease (increase in $P_{L D}$ ) and resulted in a change in $\Delta \delta$. Further tap changes will cause the system operating point to cross the voltage stability boundary highlighted as point $\mathrm{E}$ and worsen the system conditions. Fig. 9 shows the the contours of $P_{G 1}$ and $P_{L D}$ at $t=140 \mathrm{~s}$ where the aperiodic rotor angle stability boundary for $G_{1}$ is reached. 


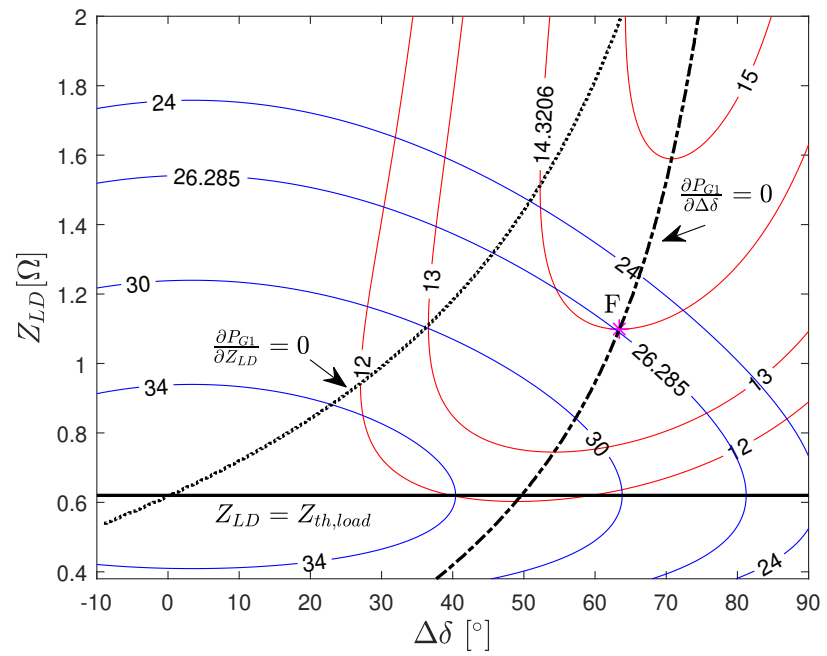

Fig. 9. Contours of constant injected power $P_{G 1}$ and constant power delivered to the load $P_{L D}$ in the $\Delta \delta-Z_{L D}$ plane at $t=140$ s.

It can be seen that voltage stability boundary has been crossed and the power delivered to the load has decreased as highlighted by point $\mathrm{F}$ in Fig. 9. Further tap changes will cause the manually excited generator $G_{1}$ to lose synchronism as seen in Fig. 7 and eventually cause a system blackout at $t=154 s$.

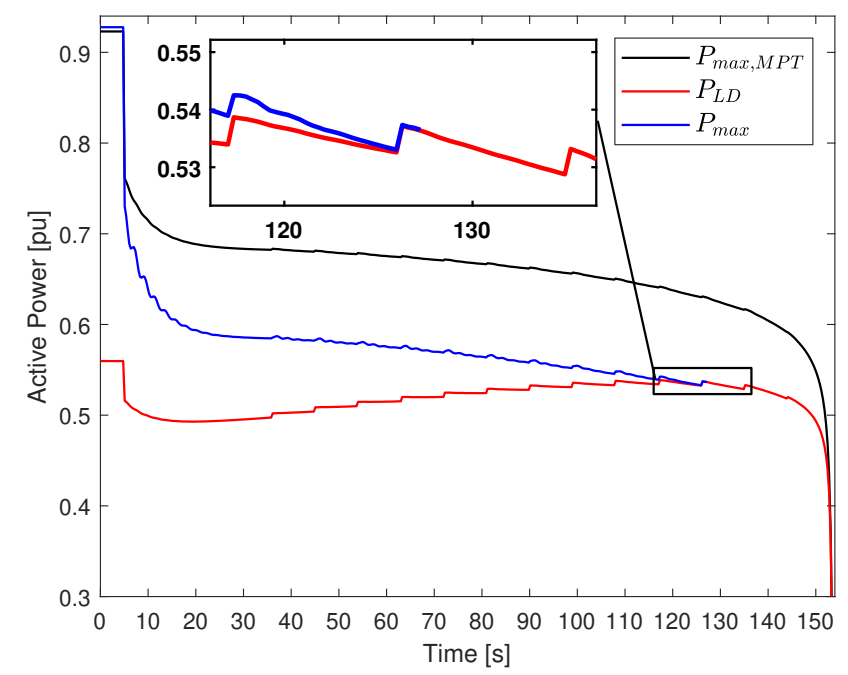

Fig. 10. Load power $P_{L D}$, maximum deliverable power to the load $P_{\max }$ based on the proposed approach and maximum deliverable power to the load $P_{\max , M P T}$ based on the Thevenin impedance matching criteria.

Fig. 10 shows how the proposed approach to determine the maximum deliverable power to the load intersects with the load power exactly once at $t=127.2 \mathrm{~s}$, which corresponds to point $\mathrm{E}$ in Fig. 8. The maximum deliverable power to the load based on the Thevenin impedance matching criteria never intersects with the load power and is therefore not able to detect voltage instability.

\section{B. IEEE 14 bus system}

A time domain simulation was performed on the IEEE 14 bus system seen in Fig 11. The system was modified where OLTC transformers were added to the buses 10-14. Initially, one of the parallel transmission lines between bus $1-2$ is out of service. Fig. 12 show a plot of highlighted bus voltage magnitudes and internal rotor angles at four different instances of time (snapshots I-IV). To provoke instability the transmission line 9-14 was tripped at $t=10 \mathrm{~s}$ (snapshot I).

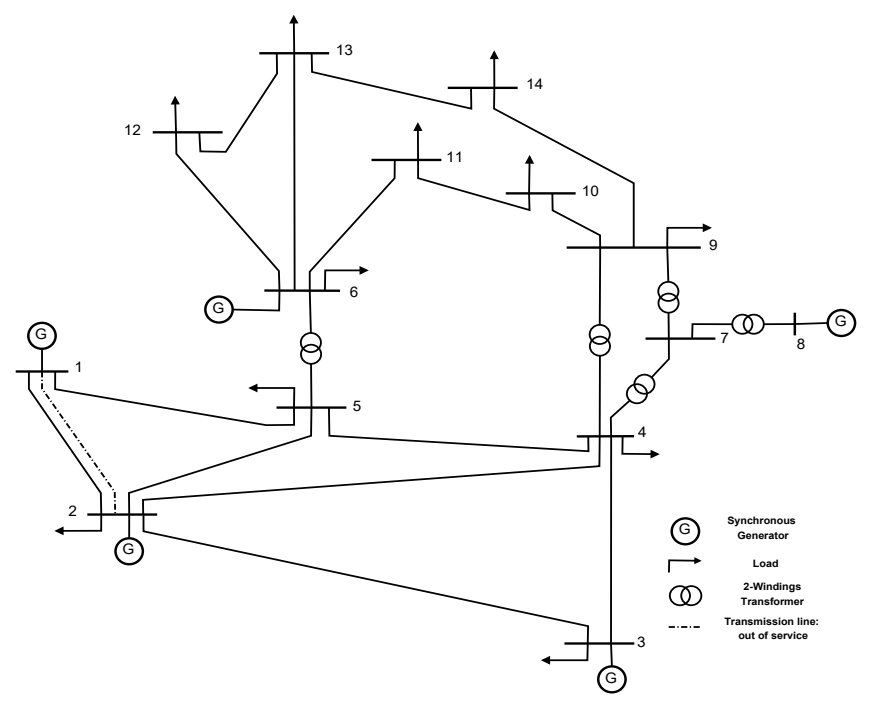

Fig. 11. One line diagram of the IEEE 14 bus system.

The disconnection of the transmission line 9-14 causes the OXL of $G_{1}$ to be activated at $t=54.3 \mathrm{~s}$ (snapshot II) and the voltages slowly start to decrease due to OLTC tap changes at buses 10-14, while the rotor angles slowly increase.
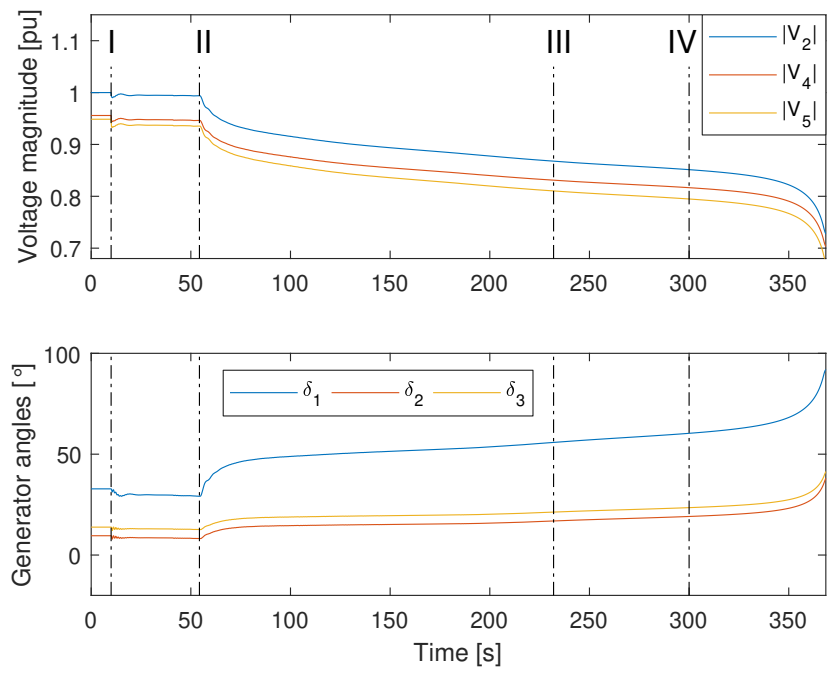

Fig. 12. Bus voltage magnitudes and internal rotor angles of selected buses and generators at four different instances.

Fig. 13 shows the load power at bus 5 and the maximum deliverable power to the load based on the proposed approach. 
The initial red-dotted maximum deliverable power to the load represents in case the OXL of $G_{1}$ was active, which becomes active at snapshot II. After the activation of the OXL, the maximum deliverable power to the load decreases and eventually intersects with the actual load power at exactly $t=232.8 \mathrm{~s}$ (snapshot III). Beyond this point the actual load power is the maximum deliverable power to the load, which continues to decrease and has a negative impact on the system. The further worsening of the system conditions leads to generator $G_{1}$ to lose synchronism at $t=300 \mathrm{~s}$ (snapshot IV) and eventually a collapse in voltage at $t=368 \mathrm{~s}$.

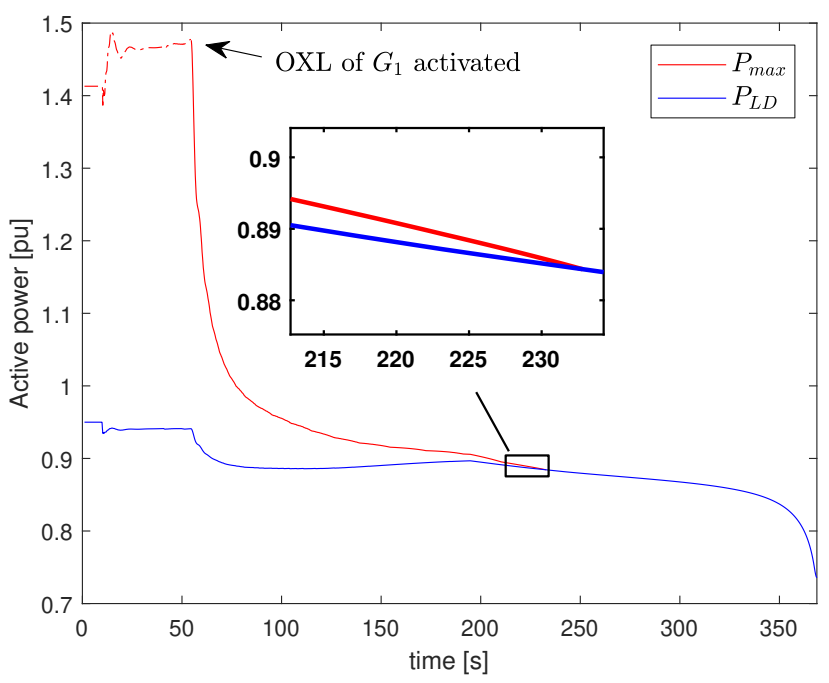

Fig. 13. Load power $P_{L D}$ at bus 5, maximum deliverable power to the load $P_{\max }$ based on the proposed approach.

\section{CONCLUSION}

This paper presented an innovative approach that was capable of detecting voltage instability $26.8 \mathrm{~s}$ before system blackout occurred for the five bus system, while the maximum deliverable power to the load based on the Thevenin matching criteria was never able to detect voltage instability. For the five bus test system, the OLTC actions caused voltage instability, which eventually caused aperiodic rotor angle instability at $t=140 \mathrm{~s}$. For the IEEE 14 bus system, the tripping of a transmission line followed by OXL activation of $G_{1}$ caused OLTC-transformers to tap change. At $t=232.8 \mathrm{~s}$ the point of maximum deliverable power to the load at bus 5 was reached and each consecutive tap change beyond this point worsened the system conditions. Eventually $G_{1}$ lost synchronism at $t=300 \mathrm{~s}$ and the system voltages collapsed at $t=368 \mathrm{~s}$. The early detection of instability gives time for remedial actions to possibly restore the system to stable conditions. The distance between the actual operating point and the improved voltage stability boundary represents the distance to voltage instability that gives valuable information about the system trajectory.

The proposed approach will be developed into a method and be further tested on larger power systems in order to investigate possible challenges with performing the analysis in real-time. The method will use developed methods that compute Thevenin equivalents in real-time. This approach will be useful for power systems with a large share of RES and their fluctuating behaviour, which can cause the power system to operate closer to its limits.

\section{REFERENCES}

[1] R. N. Stavins and R. C. Stowe, The Paris Agreement And Beyond: International Climate Change Policy Post-2020, Harvard Project on Climate Agreements, October 2016.

[2] Energy Strategy 2050 - from coal, oil and gas to green energy, The Danish Ministry of Climate and Energy, February 2011.

[3] H. Jóhannsson, A. H. Nielsen and J. Østergaard, Wide-area assessment of aperiodic small signal rotor angle stability in real-time, IEEE TRANSACTIONS ON POWER SYSTEMS, vol. 28, November 2013

[4] H. Jóhannsson, J. Østergaard and A. H. Nielsen, Identification of critical transmission limits in injection impedance plane, Int. J. Elect. Power Energy Syst., vol. 43, December 2012.

[5] S. H. Sommer and H. Jóhannsson, Real-Time Thevenin Impedance Computation, 2013 IEEE PES Innovative Smart Grid Technologies

[6] H. Morais, P. Vancraeyveld, A. H. B. Pedersen, M. Lind, H. Jóhannsson and J. Østergaard, SOSPO-SP: Secure operation of sustainable power systems simulation platform for real-time system state evaluation and control, IEEE TRANSACTIONS ON INDUSTRIAL INFORMATICS, vol. 10, November 2014.

[7] M. Glavic and T. Van Cutsem, Wide-area detection of voltage instability from synchronized phasor measurements. Part I: Principle, IEEE Transactions on Power Systems, vol. 24, no. 3, pp. 14081416, 2009.

[8] M. Glavic and T. Van Cutsem, Wide-Area Detection of Voltage Instability From Synchronized Phasor Measurements. Part II: Simulation Results, IEEE Transactions on Power Systems, vol. 24, no. 3, pp. 14171425, Aug. 2009.

[9] I. Smon, G. Verbic, and F. Gubina, Local voltagestability index using tellegens theorem, Power Systems, IEEE Transactions on, vol. 21, no. 3, pp. 12671275, 2006.

[10] R. Diao et al., Decision tree-based online voltage security assessment using рти measurements, Power Systems, IEEE Transactions on, vol. 24 , no. 2, pp. $832839,2009$.

[11] A. Perez, H. Jóhannsson, P. Vancraeyveld and J. Østergaard, Suitability of voltage stability study methods for real-time assessment, in Innovative Smart Grid Technologies Europe (ISGT EUROPE), 2013 4th IEEE/PES, Oct 2013, pp. 1-5.

[12] M. Glavic and T. Van Cutsem, A short survey of methods for voltage instability detection, Power Energy Society General Meeting, pp. 18, 2011

[13] $\mathrm{W} . \mathrm{Li}, \mathrm{T}$. Chen, and $\mathrm{W} . \mathrm{Xu}$, On impedance matching and maximum power transfer, Electric Power Systems Research, vol. 80, no. 9, pp. $10821088,2010$.

[14] A. Perez, H. Jóhannsson, K. Martin and J. Østergaard, Improved Thvenin equivalent methods for real-time voltage stability assessment, IEEE International Energy Conference 2016, Leuven, Belgium

[15] A. Perez, H. Jóhannsson and J. Østergaard, Wind farms generation limits and its impact in real-time voltage stability assessment, in PowerTech, 2015 IEEE Eindhoven, June 2015, pp. 1-5.

[16] A. Perez, H. Jóhannsson, P. Lund and J. Østergaard, Evaluation of HVDC interconnection models for considering its impact in real-time voltage stability assessment, Modern Electric Power Systems 2015, 2015, Wroclaw, Poland

[17] J. Zhao, Y. Yang, and Z. Gao, A review on on-line voltage stability monitoring indices and methods based on local phasor measurement, in 17th Power Systems Computation Conference, 2011, Stockholm, Sweden

[18] H. Jóhannsson, Development of Early Warning Methods for Electric Power Systems, Ph.D. Thesis, Technical University of Denmark, Department of Electrical Engineering, Centre for Electric Power and Energy, 2011. 